\title{
Research on the Coupling Relationship Between Advertising Slogans and Regional Culture in Inner Mongolia
}

\author{
Jian Zhao ${ }^{1, *}$ Qi Jia ${ }^{1}$ \\ ${ }^{1}$ Inner Mongolia University \\ ${ }^{*}$ Corresponding author. Email: 1136313536@qq.com
}

\begin{abstract}
Language serves as the material carrier of culture. Advertising slogans manifest the cultural heritage, development concept and value system of an enterprise or even a region, of which the language characteristics, social applications and national psychology exert considerable influence on both consumers and audiences. This study, from the perspective of the coupling relationship between advertising slogans and regional culture, explores the linguistic characteristics of the advertising slogans in Inner Mongolia in terms of phonetic rhetoric, specific rhetoric and linguistic structure influenced by regional culture, followed by the analysis of their coupling relationship of mutual influence and promotion. The interpretation of advertising slogans is of great significance for enhancing the effect of advertisement in Inner Mongolia, highlighting the cultural connotation of regional advertising slogans and boosting the regional brand image of Inner Mongolia. Further delving into the excellent history and culture of different ethnic groups in Inner Mongolia is expected to better inherit the national spirit.
\end{abstract}

Keywords: Inner Mongolia, advertising slogans, regional culture, rhetoric art, coupling relationship.

\section{INTRODUCTION}

"Modern advertising represents public, non-face-to-face information dissemination activities in which advertisers pay a certain price to convey specific information, which has been scientifically refined and artistically processed, to the target audience through the communication media for the purpose of changing or strengthening the public's ideas and behaviors" [1]. In particular, advertising slogans, as the carrier and the soul of advertising, mirrors a specific culture, with distinctive image, locality, nationality and culture. The design of advertising slogans to win the favor of consumers has grown into one of the effective competitive tactics for businesses. Scholars have interpreted the language structure, social application and national culture of advertising slogans from multiple perspectives. Aan Niekerk Angelique (2020) [2] elaborated on the play of sentence structure in advertising language and put forward the requirement of regulating the use of sentences whose syntax does not conform to grammatical rules; $\mathrm{Fu}$ Yaolu (2016) investigated and studied the cases related to the copyright protection of advertising slogans with a view to accurately delineating the boundaries of the recognition of advertising slogan copyright [3]; Yang Jian (2012) [4] pointed out that the process during which modern advertising draws nutrients from national culture and enhances image from the perspective of culture and psychology opens up a new way for the transmission of national culture. All proved that the research on advertising slogans has a certain theoretical foundation. However, there are few studies on the relationship between advertising slogans and regional culture, especially the theoretical gap in the analysis of regional culture conveyed by advertising language in Inner Mongolia. Special geographical location of the ethnic minority in the western frontier of Inner Mongolia, on the strength of its rich cultural resources, has contributed to multifarious advertisements with regional cultural characteristics. Hence, its cultural value and regional image are worthy of our inheritance and protection. This paper analyzes the linguistic phenomenon of advertising slogans and the implied cultural connotation from the perspective of linguistics, culture, ethnology, statistics and other disciplines by adopting 174 collected and compiled advertising slogans with Inner Mongolian characteristics as 
examples. Besides, the path of development of advertising slogans in Inner Mongolia in the new era is explored, aiming to further explore and promote the excellent traditional culture of different ethnic groups and promote the diversified and inclusive development of advertising slogans and culture in Inner Mongolia.

\section{THE LANGUAGE CHARACTERISTICS OF ADVERTISING SLOGANS IN INNER MONGOLIA}

Advertising slogans function as the core of advertising. In the modern society with unprecedented cultural prosperity, rapid economic development and great abundance of commodities, multifarious advertising slogans are found everywhere in stores, buildings, streets and media. A wonderful advertising slogan is often able to win the attention of consumers and trigger the emotional recognition and resonance of the audience. In the wake of the rapid development of the market economy, the increasingly diverse advertising slogans have undergone a transformation from monolithic to pluralistic, from simple statements to rhetorical ones. The study of advertising slogans also involves different aspects such as phonetic rhetoric, specific rhetoric and language structure.

\subsection{Phonetic Rhetoric of Advertising Slogans in Inner Mongolia}

Phonetic rhetoric resorts to rhyme, rhythm, level and oblique tones, reiterative locution, homophonic words, onomatopoeia, and alliteration to make advertising slogans readable, and thus to deepen the audience's impression of the products in a specific integrated context of thought. Among the 174 examples of advertising slogans in Inner Mongolia in this paper, it is found that the use of rhyme and homophonic words account for a relatively large proportion of the slogans, which will be analyzed in the following stage in accordance with the actual corpus.

\subsubsection{Rhyme}

The advertising slogans in Inner Mongolia have the common features of simple structure and strong rhythm. They are designed to attract the audience through the rhyme, which is used flexibly to strengthen the distinctive personality of the advertisement and make it easy to remember. For example, the advertising slogan of "Gadamerlin" brand as the specialty in Inner Mongolia goes like Shi Dai Cao Yuan Ying Xiong, Chuan Cheng Zhong Gu Jue Song (meaning the generations of grassland heroes contributed to the inheritance of a thousand ancient ode"), where Xiong rhymes with Song, indicating that the brand "Gadamerlin" is well known by virtue of its long history of legend; and Cao Yuan Zhi Gen, Lyu Se Zhi Ben (meaning the root of the grassland and the origin of the green), where Gen rhymes with Ben, highlighting the characteristics of grassland culture of the brand, as well as reflecting the safe and nutritional quality of the specialty products. Another example is the advertising slogan of koumiss, which goes like Yin Jiu Bi Si Yuan, Nan Wang Mo Zhong Quan (meaning the thinking of the source while drinking and remembering the spring in the desert), where Yuan rhymes with Quan; and $M a$ Zhu Shui Cao, Ren Yang Tong Lao (meaning the horses follow the water and grass and people depends on koumiss). Koumiss is the fermented milk naturally formed by nomads in the process of long-distance ups and downs, with a long history of origin. It is regarded as a holy drink by nomads, which is memorable when you think of its source. Another example is the advertising slogan of Hohhot's city image, going like Cao Yuan Feng Yun Zou Lang, Si Ji Yang Sheng Tian Tang (meaning the elegant corridor of the prairie and the health paradise during four seasons), and $H u$ Shi Feng Guang Sai Tian Tang, Zhao Cheng Shen Yun Pin Lai Xiang (meaning the scenery of Hohhot competes with heaven, summoning the charm of the city to incense), where Lang rhymes with Tang, and Tang rhymes with Xiang. Hohhot is the capital city of Inner Mongolia Autonomous Region, whose northern grassland civilization and nomadic culture are highlighted as the city card for publicity. The advertising slogan is easy to transmit, remember and read, and helps to build a thematic cultural city based on its unique resources and advantages.

\subsubsection{Homophonic Words}

Advertising slogans in Inner Mongolia often use homophonic words to enhance the expression effect and thus generate rhetorical interest. For example, the advertising slogan of Hetao Liquor goes like Jiu Zhong Kui Shou, Yin Yi Wei Hao (the leader of liquor makes people proud of drinking), where "Yin" is a pun in the Chinese context. It is intended to express the high status of Hetao Liquor among many kinds of liquors and to meet the audience's psychological demand for purchasing; Yin Wei You Liang Xin, Suo Yi Geng Fang $X i n$ (the conscientiousness disburdens your worries), where Liang has double meanings in Chinese, thus emphasizing the high quality of The Tou Liquor's quality production from "grain" and the high credit of the brand. Another example is the tourism advertising slogan of Chifeng City, going like Hong Shan Huang Shui, Chi Feng Zui Mei (with red mountains and yellow water, Chifeng is the most exquisite", where Zui (the most) is the homophonic word. The words that tourists like to see are applied to the advertising slogan, highlighting the beautiful scenery of Chifeng City, which is intoxicating and more attractive to tourists. 


\subsection{The Specific Rhetoric of Advertising Slogans in Inner Mongolia}

In the creation of advertising slogans, advertisers often use rich rhetoric such as puns, parallelism, euphemisms and exaggerations to make the language more distinctive as a powerful means of advertising promotion to win the favor of consumers. The following analysis will focus on metaphors and antithesis based on the actual corpus collected.

\subsubsection{Metaphor}

The use of metaphors is the most common in the advertising slogans in Inner Mongolia, and its charm lies in the fact that it is easy to understand, which highlights the great characteristics of the subject, and achieves an interactive effect with the audience group [5]. For example, the advertising slogan of Inner Mongolia's specialty air-dried beef goes like "original flavor of dried beef is Khan's invitation letter", which compares dried beef to the invitation letter of the regional chief, highlighting the dignity of dried beef as a characteristic national food and its brand status. Due to its vivid and evocative characteristics, the use of metaphors in many city image advertising slogans in Inner Mongolia is extensive, such as Hinggan League is reputed as, "red cradle, green fertile land". This city is picturesque all year round, intersecting four grasslands, 50 volcanoes, 50 hot springs, with luxuriant natural resources. For example, Alxa League is known as "heavenly Alax", and there are two green ribbons of Helan Mountain and Qilian Mountain stretching far away. There is a golden land full of Gobi and desert and also a simple spirit of helping and supporting each other from generation to generation. The "heavenly Alax" is a holy place for human beings to get away from the hustle and bustle and taste the harmony between man and nature.

\subsubsection{Antithesis}

In the advertising slogans of Inner Mongolia, the use of antithesis is very extensive. According to An Introduction to Rhetoric, "any speech in which two sentences of equal word count and similar syntax are arranged successfully in pairs is called the antithesis" [6]. Its characteristics are the same sentence pattern, the same number of words and the similar nature of words. For example, Zhuang Mei Nei Meng Gu, Liang Li Feng Jing Xian (magnificent Inner Mongolia with beautiful scenery), Gong Tong Tuan Jie Fen Dou, Gong Tong Fan Rong Fa Zhan (common unity and struggle, common prosperity and development), and De Xing Tian Xia, Xiao Chuan Wan Jia (virtue prevails in the world, filial piety is passed on in all families). As a non-commercial advertising language, public service advertising language has strong sociality, so it uses antithesis to facilitate the transmission and memory of positive energy in advertising language. Another example is the advertising slogan of Inner Mongolia "Little Sheep" Catering Enterprise Co., Ltd., going like Zhong Guo Mei Shi, Shi Jie Gong Xiang (China Cuisine, shared by the world). The Company, known as the "No.1 Chinese hotpot", has gone global, with several branches in the United States, Canada and Japan. The antithesis makes the preceding and following meaning of sentences complement each other and thus enhance the rhythm and musical beauty of the slogan.

\subsection{Language Structure of Advertising Slogans in Inner Mongolia}

The existing research on advertising slogans mainly focuses on language skills and rhetorical tactics, while there is less analysis on its language structure. The author found that two simple language structures are mostly used in Inner Mongolia that one is the "three + three" and "four + four" structure, i.e., most of the advertising slogans are composed of six or eight syllables with three or four syllables before and after; and the other is the "verb + noun + (adjective)" structure. These two concise language structures are more often found, and the root causes include the following three points. Firstly, the advertising slogans in Inner Mongolia have common features of advertising slogan design. The motive of advertising slogans is to recommend and promote, and in this process, words and phrases are usually made simple in order to deepen the impression and make it easier to remember. Secondly, Inner Mongolia has a long history and culture, and its western dialect belongs to the Jin language system, which directly inherits the ancient Qin and Jin languages and retains a large number of ancient language features [7]. The Book of Songs is the first collection of poetry in China, and its basic stanzas are mainly in quatrains, going like Cen Ci Xing Cai, Zuo You Liu Zhi. Yao Tiao Shu Nyu, Wu Mei Qiu Zhi (water flows left and right, of cress long here, short there; the youths yearn for each other day and night, for the good maiden fair). The language is abbreviated and short, concise and meaningful, which makes it easy to circulate widely among the people. The language of Inner Mongolia is influenced by the historical and traditional culture, so it also has its own characteristics. Thirdly, Inner Mongolia is a region inhabited by ethnic minorities, with diversified ethnic groups and languages. A simple and stable advertising slogan is easy to understand and better adapted to reality, thus expanding the audience, promoting the spread of Chinese culture and enhancing the historical identity of each ethnic group. The nature of advertising slogans and the historical and realistic conditions have influenced the linguistic structure of advertising slogans in Inner Mongolia, and this paper will give examples of these two structures below. 


\subsection{1. "Three + three" and "four + four" structure}

The structure of "three + three" and "four + four" is characterized by simplicity and relative stability. In addition to fixed structures of antithesis such as Tian Tang Cao Yuan, Mei Li Qing Cheng (paradise grassland, charming Qingcheng), there are also many flexible non-fixed structures, which use progressive relationships syntactically and semantically to express the role of related commodity enterprises. For example, Mei Yi Tian, Wei Ming Tian (every day is for tomorrow) (Mengniu Dairy), Tian Fu Shen Yun, Dan Ya Nong Xiang (talented charm, elegant fragrance) (Hetao Liquor Group Co., Ltd.), Lv Hua Sha Mo, Mei Li Zhong Guo ("green desert, beautiful China") (Yili Resources Group), Tian Tang Cao Yuan, Mei Li Qing Cheng (paradise grassland, charming Qingcheng) (Hohhot city image advertising slogan). In particular, Mei Yi Tian, Wei Ming Tian (every day is for tomorrow) highlights the safe and nutritious quality of Mengniu dairy products, which makes life more promising. Another example is Lv Hua Sha Mo, Mei Li Zhong Guo (green desert, beautiful China), in which Yili Resources Group is committed to ecological restoration and eco-industry from desert to city, leading the global desert green economy and creating an ecological civilization construction model that affects the world. This structure also often uses adjectives in the lexical arrangement, highlighting the image characteristics of product activities, arousing the audience's interest and making them desire to know more about it or buy it. For example, Tian Fu Shen Yun, Dan Ya Nong Xiang (talented charm, elegant fragrance) shows the deliciousness of Hetao King Liquor through the arrangement of adjectives such as "elegant" and "strong fragrance".

\subsection{2. “Verb + Noun + (Adjective)" structure}

Another common structure of Inner Mongolia advertising slogans is "verb + noun + (adjective)", which is unified with more simple sentences and fewer compound sentences. It is characterized by a small number of words, basically five to seven words, usually in one sentence, which makes the focus prominent and powerful. For example, "Nourishing your vitality" (Yili Industrial Group Co., Ltd.), "Delivering energy with heart" (Yitai Group Co., Ltd.), "To warm the world" (Erdos cashmere sweater), and "To make limited resources unlimited" (Mengtai Coal Group). In particular, "Nourishing your vitality" highlights the fact that Yili Group, as an industry growing up on the grasslands, continues to produce products representing health and vitality in the inheritance and succession of grassland culture; In "To make limited resources unlimited", the use of the imperative powerfully expresses that Mengtai upholds the people-oriented value concept and creates social value by building an evergreen foundation.

\section{ANALYSIS OF THE REGIONAL CULTURE OF ADVERTISING SLOGANS IN INNER MONGOLIA}

Throughout the history, Inner Mongolia region has formed different grassland cultures and red cultures with ethnic flavor, which carry the memory of a nation. As a significant carrier, advertising slogans have played a positive role in spreading the culture of minority regions and extending the spirit of the Chinese nation.

\subsection{Inclusive and Centurial Grassland Culture}

Grassland culture refers to a culture created by the ancestors, tribes and ethnic groups who have been living in the grassland area for generations, which is adapted to the grassland ecological environment and mainly concentrated in the vast grassland area in the north of China, representing the source of Chinese culture and the dawn of Chinese civilization [8]. The advertising slogans of the Inner Mongolia region profoundly show the minority flavor contained in the grassland culture and thus give people a cultural identity.

\subsubsection{Physical culture: beautiful and vast grassland scenery}

"The beautiful prairie is my home, breeze blowing the green grass and blossoms everywhere." Inner Mongolia has unique grassland scenery, including Gegentala grassland, Hulunbuir grassland, Horqin grassland, etc. In order to highlight the characteristics of grassland, many advertising slogans use the imagery of "grassland", such as Inner Mongolia specialty liquor advertising slogan going like "grassland soul, green rain"; Hohhot city image advertising slogan like "paradise grassland, beautiful Qingcheng"; and Inner Mongolia tourism advertising slogan "trace the footprints of Genghis Khan, feel the cultural evolution of the grassland". Grassland scenery has turned into a bright brand of green Inner Mongolia.

\subsubsection{Language and culture: unique and pure Mongolian language}

The Mongolian language is the result of the Mongolian people's long history and culture of material production and spiritual creation. Many advertising slogans in Inner Mongolia are also influenced by Mongolian language, such as "Not all milk could be called Milk Deluxe (Teruun Suu)", where "Teruun Suu" means "the best" in Mongolian. "I come from the grassland, Unglima Koumiss", where "Unglima" means "fragrant" in Mongolian. In addition, most of the names of Inner Mongolia's "league", "city" and "banner" are 
deduced from the Mongolian language, which is also reflected in the city image advertising slogans. For example, "Travel through thousands of mountains and rivers, Hulun Buir is drunkenly beautiful"; "Hulun" is the phonetic transcription of the Mongolian word, which means "otter", and "Buir" means "male otter"; and "Hulun Buir" is named after Hulun Lake and Buir Lake. In the slogan of "One step west of Beijing is Ulanqab", "Ulanqab" means "red mountain pass"; and "building a richer, more beautiful and happier Xilingol", where "Xilingol" means "hilly-area river".

\subsubsection{Behavioral culture: colorful food folklore}

Food production: Due to their special nomadic lifestyle, the Mongolian people live by herding and water and grass, so their food habits are more original, and they have produced many Inner Mongolian specialties including Mongolian liquor, Mongolian tea, hand-served mutton, beef jerky, Mongolian cheese, etc. Many advertising slogans also reflect the long traditional production culture; for example, the advertising slogan of Mongolian Liquor King, "Mongolian Liquor King: greetings from the grassland", and the advertising slogan of Inner Mongolia's specialty air-dried beef-like "from the ecological grassland, selected healthy ingredients". Genghis Khan swept across the Eurasian continent during his conquests on the grasslands, reaching as far as ancient Rome; and in order to facilitate the march, they slaughtered cattle and sheep and boiled them in water, resulting in "boiled sheep"; sometimes the remaining meat was dried in the sun to make it easier to carry, resulting in "beef jerky". Because of the abundance of cattle and sheep in Inner Mongolia, the cows calved too much, and the herdsmen brewed milk into dairy products, resulting in "dried milk cake" and "milk tablets".

Folk life: The integration and reproduction of different ethnic groups have left a rich historical treasure for Inner Mongolia. For example, in "a generation of Heavenly Kings led their bows, and the men fought for Naadam." The "Naadam" conference, formerly known as the "Ovoo Festival", is a traditional festival set by the Mongolian people to celebrate a good harvest. It is used to pray for the happiness and peace of the family. The traditional events such as wrestling, horse racing, archery, etc., the rousing sound of the horse-head fiddle, and the clear songs and dances of young men and women show the youth and vitality of the Mongolian people, and express the joy of the people; another example goes like "not missing a yurt, not leaving a herder behind". The Ulanmu riding is a grassland arts and culture organization created by the Inner Mongolia Autonomous Region. They serve the people whole-heartedly, pass on the traditional spiritual culture of Inner Mongolia through various forms of performance, and promote the unity and struggle of all ethnic groups. In addition, the combination of Mongolian short folk songs and Han Chinese climbing tunes has given birth to the Manhan tune, and the Mongolian form of historical storytelling, borrowing from Han Chinese book reviews, has given rise to the Uligar, which has produced many folk customs with ethnic characteristics.

\subsubsection{Spiritual culture: the character of simplicity and boldness}

Respect for ecological nature: Mongolian people respect nature, which is closely related to the long-term nomadic life. For example, in "Grassland essence, healthy green card", the traditional hunting and herding production makes people strongly dependent on the natural environment and pay more attention to the naturalness and health of food; and the advertising slogan of Yili Resources Group of "Green desert, beautiful China", implies the ecological trend of the grassland. In recent years, China has reformed its nature protection system, and the Inner Mongolia grassland, which has suffered a serious ecological crisis, has also launched a green defense war, realizing the retirement of grazing and grass, and building a beautiful ecological home through zoning rotational grazing, grass replanting and other ways.

Worship of national heroes: National heroes are the brightest coordinates of a nation and an important part of national culture. The people of Inner Mongolia have always had the national psychology of reverence for heroes, and the word "hero" has been mentioned many times in advertising slogans, such as "Enjoy the taste of grassland, enjoy the ode to heroes" and "Heroes have no words, while word of mouth is passed on." Genghis Khan, as we know it, built a powerful Mongolia in half his life. Gadamerlin is also a national hero of the Mongolian people. In order to protect the Mongolian nation's pasture and land, he fights for life. To fight against the Mongolian princes and warlords, he sacrificed his life. The people have high respect for these national heroes, so they are reflected in the advertising slogans.

\subsection{Red Culture that Unites the National Spirit}

During the past two thousand years, various ethnic groups in Inner Mongolia have exchanged and integrated with each other, gradually forming a red culture that unites the national spirit. The slogans, such as "Northern China, Splendid Inner Mongolia" and "Solidly Promoting High-Quality Economic Development, Firmly Advancing National Unity and the Stability of Border Areas," reflect the inclusive, open and courageous cultural character of Inner Mongolia. Language is the most important tool of communication. Except for imagery, language plays an indisputable role 
in emotional advertising, for it can regulate desired emotional effects, identities, and appeals [9], and thus has become a significant factor in the formation of cohesion among various ethnic groups. In the advertising slogans of Inner Mongolia, the red culture is mainly embodied in the promotion of the excellent culture of ethnic minorities and the love for the country. The enterprises in Inner Mongolia endeavor to develop into a united entity to make contributions to the motherland and pursue social benefits. For instance, Inner Mongolia Xi Meng Group Co., Ltd. upholds the mission of "serving the country with industry and benefiting the society."

With the philosophy of "Ecological Town Expansion and Immigration, Industry-driven Poverty Alleviation," Dongda Mongolia King Winery Co. Ltd. is dedicated to industry-driven poverty alleviation and helping strengthen the ability of poor areas to tap into their development potential. Since the 18th CPC National Congress, China has tackled challenges and difficulties with unprecedented scope, strength and speed, achieving remarkable results in poverty alleviation. Many enterprises in Inner Mongolia have taken up the heavy responsibility to innovate the way of poverty alleviation. For instance, Langege Dairy Co., Ltd. and Caoyuan Xinhe Food Co., Ltd. have been listed as excellent leading enterprises in the 13th Five-Year Plan of Inner Mongolia for poverty alleviation, which have conducted a unique cultural promotion for ethnic unity and also made solid contributions to the cause of poverty alleviation in Inner Mongolia. The Inner

Table 1. Selected Examples of Various Advertising Slogans in Inner Mongolia and the Number of Regional Cultures Mentioned

\begin{tabular}{|c|c|c|c|c|c|c|}
\hline Category & No. & Example & \multicolumn{4}{|c|}{ No. of Regional Cultures Mentioned } \\
\hline \multirow[b]{2}{*}{ Product Slogan } & \multirow[b]{2}{*}{107} & \multirow[b]{2}{*}{$\begin{array}{l}\text { 1. Praising the Grassland Hero, Passing on the Greatest Ode } \\
\text { (Advertising slogan of "Gada Meilin" brand, a special product } \\
\text { of Inner Mongolia) } \\
\text { 2. Greetings from the Grassland (Dongda Mengolia King } \\
\text { Wine) } \\
\text { 3. A Delicacy from the Grassland (Advertising slogan of dried } \\
\text { beef, a specialty of Inner Mongolia) } \\
\text { 4. Not every milk deserves the name Milk Deluxe. }\end{array}$} & $\begin{array}{c}\text { Grassland } \\
\text { Culture }\end{array}$ & Food Culture & Folk Culture & Red Culture \\
\hline & & & 42 & 87 & 5 & 0 \\
\hline $\begin{array}{l}\text { Promotion } \\
\text { Slogan }\end{array}$ & 55 & $\begin{array}{l}\text { 1. Exploring Scenic Spots and Historical Sites in the Amazing } \\
\text { Chifeng (Advertising slogan for city image of Chifeng city) } \\
\text { 2. Northern China, Splendid Inner Mongolia } \\
\text { 3. Grassland Culture Marking the Best in the World, Green } \\
\text { Civilization Leading the Way }\end{array}$ & 31 & 0 & 0 & 14 \\
\hline $\begin{array}{l}\text { Corporate } \\
\text { Slogan }\end{array}$ & 12 & $\begin{array}{l}\text { 1. Greening the Desert, Making China Beautiful (Elion) } \\
\text { 2. Every Day for Tomorrow (Mengniu Dairy) } \\
\text { 3. Making the Limited Resources Unlimited (Mengtai Group) }\end{array}$ & 5 & 4 & 0 & 3 \\
\hline
\end{tabular}

Mongolia Autonomous Region has gradually formed its unique culture of poverty alleviation through targeted and precise poverty alleviation, showing the great national spirit of shared prosperity and common development among all ethnic groups.

\section{COUPLING RELATIONSHIP BETWEEN ADVERTISING SLOGANS AND REGIONAL CULTURES IN INNER MONGOLIA}

\subsection{Analysis of Advertising Slogans and Regional Cultural Characteristics in Inner Mongolia}

Inner Mongolia is a typical multi-ethnic autonomous region, where 49 ethnic groups, including the Han Chinese, live and have developed a rich and colorful regional culture through long-term interaction and integration. According to the statistics, among the 174 advertising slogans in Inner Mongolia, there are 107 product slogans (see Table 1), accounting for $61 \%, 32$ promotion slogans, taking up $32 \%$, and 12 corporate slogans, making up 7\%. The regional cultures reflected in the advertising slogans have their own focuses, among which 78 slogans embody the grassland culture, accounting for $45 \%$, and 17 slogans represent the red culture, accounting for $10 \%$. It can be seen that the advertising slogans and regional cultures in Inner Mongolia are characterized as follows. 
Firstly, the product advertising slogans account for the largest proportion, while the promotion and corporate advertising slogans take up a relatively small proportion. Inner Mongolia is one of the ancient historical cradles of the Chinese nation and the place where the ethnic minorities of northern China lived and thrived in ancient times, and its economy has developed over a long period of time. On the one hand, located at the hub of the Grassland Silk Road, an important trade route between China and the West in ancient times, Inner Mongolia has witnessed prosperous commercial activities, and minority regimes such as the Uyghur and Mongolian minorities have also made important contributions to the further commercial development of the region. Since the reform and opening up, Inner Mongolia has achieved high-quality economic development by implementing industrial transformation and supply-side structural reform. On the other hand, promotion advertising slogans mainly serve to promote local tourism resources, ecological protection and related national policies, and have gradually emerged and developed in recent years, thus accounting for a relatively small proportion in advertising slogans.

Secondly, the slogans involving grassland culture account for the largest proportion. The unique geographical location and superior environment of Inner Mongolia have formed the grassland culture with ethnic charm, which is the most wonderful part of product, promotion and corporate advertising slogans. Both the people and enterprises in Inner Mongolia are proud of the grassland culture. By showing the profound grassland culture of Inner Mongolia, the advertising slogans can attract the attention of the audience and make Inner Mongolia "go global," thus enriching the lives of the people and endorsing the region.

Thirdly, the slogans involving red culture make up a small proportion in product advertising slogans but a large proportion in promotion and corporate slogans. Red culture was created by the Chinese Communists, advanced elements of the masses and the people during the years of the revolutionary war, and is an advanced culture with great Chinese characteristics, which contains a rich revolutionary spirit and profound historical and cultural connotations. Since product advertising slogans possess a commercial nature, they absorb and publicize less red culture, while the promotion advertising slogans are more suitable for the dissemination of red culture due to their special nature of promotion as the purpose.

\subsection{Coupling Relationship Between Advertising Slogans and Regional Cultures in Inner Mongolia}

Advertising slogans and regional cultures in Inner Mongolia interact and influence each other (see Figure 1). The advertising slogans in Inner Mongolia contain common rules of advertising language, and meanwhile, influenced by the regional cultures, the advertising slogans also have their special characteristics in the use of phonetic rhetoric, specific figure of speech and language structure. For example, the Mongolian language has a liberal phonetic combination and has expanded the Chinese vocabulary. The Mongolian people respect heroes and warriors and often use the word "Bart" in their names, and under its influence, keywords such as "hero" are often used in advertising slogans. The regional cultures of Inner Mongolia are mainly the grassland culture, and the red culture has gradually emerged under the relevant policies in the related times. The people of Inner Mongolia have lived and worked in the grasslands and have produced the unique language, behaviors and spiritual cultures on this basis, which form a circular system together and develop continuously by integrating with each other. These cultures have developed and enriched themselves by using advertising slogans as a carrier for communication and also keeping pace with the times. The influence of advertising slogans and regional cultures in Inner Mongolia is manifested in a relatively single way, with more key words involving "grassland" and "hero" and less other expressions. However, it is an eternal principle that advertising slogans and regional cultures in Inner Mongolia alternate and complement each other, which also provides a direction for the diversified design of advertising slogans in this region in the future. 


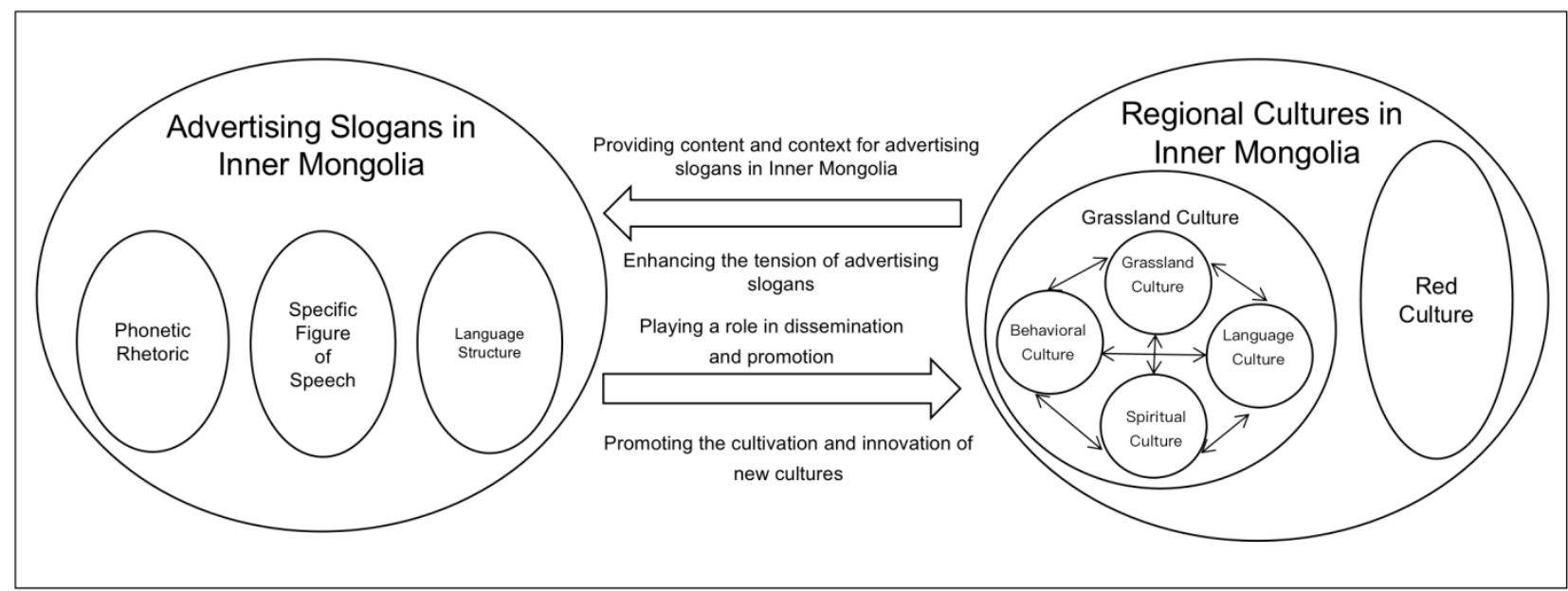

Figure 1 Diagram of Coupling Relationship Between Advertising Slogans and Regional Cultures in Inner Mongolia

\subsubsection{Influence of Regional Cultures on Advertising Slogans in Inner Mongolia}

For thousands of years, based on natural geography, environmental climate, political economy and other differences, various regions have nurtured different regional cultures with diverse characteristics through long-term historical evolution and continuous integration. The cultures have greatly influenced both the lives of people in all aspects and the advertising slogans. Meanwhile, audiences in different regions have different psychology and habits of accepting advertising slogans, which subconsciously affects the thinking view of advertisers and makes them spontaneously consider regional culture and design advertisements to resonate with audiences.

Regional cultures can provide contents and contexts for advertising slogans in Inner Mongolia. Applying regional cultural elements to advertising creativity enables to create a strong vernacular cultural atmosphere [10]. The grassland culture embraces the grassland scenery, the Mongolian language, the food and folklore, and the spirit of simplicity and boldness, all of which have become a great advantage to enrich the content of the advertising slogans in Inner Mongolia. Moreover, regional cultural elements such as blue sky, white clouds, horses, Urtiin duu and Mongolian dances reflect the unique cultural phenomenon of the grassland people and inspire people's imagination, thereby creating a broad stage for the design and development of advertising slogans in Inner Mongolia.

The regional cultures can also enhance the tension of the advertising language in Inner Mongolia. The values and emotional concepts embodied in modern advertisements generate a great impact on the audience with powerful linguistic tension, which further attracts their attention [11]. The revolutionary spirit, national unity, poverty alleviation and other advanced symbols of the times contained in the red culture are closely integrated with the core socialist values of the new era, making it easier to provoke the recognition and acceptance of the audience, meeting the socio-cultural psychological demands of consumers, and enabling the red culture in Inner Mongolia to develop with the integration of tradition and modernity in terms of content and creativity. For example, the event of "Three Thousand Orphans Entering Inner Mongolia" and other famous stories about national unity not only inherit and promote the excellent traditional cultures of Inner Mongolia, but also further highlight the outstanding quality and profound connotation of the red culture of Inner Mongolia Autonomous Region. In addition, they have also become the distinctive characteristics of the advertising slogans of this region, inspiring the cultural complex with emotion, and they have finally served as an emotional link between the brand and the audience.

\subsubsection{Role of Advertising Slogans on Regional Cultures in Inner Mongolia}

Originating from different cultural environments, advertising slogans can communicate and comprehend each other through the ingenious design of language, and are bound to yield a certain effect on local regional cultures as a means of publicity. The elements and values of regional cultures embody their own unique pursuits in advertising slogans, and are also developed through transmission.

Advertising slogans have played a role in spreading and promoting the regional cultures of Inner Mongolia. Since regional cultures manifest the ecology, customs and spirit of an ethnic group, the wide circulation of advertising slogans has gradually deepened people's understanding of the regional cultures of Inner Mongolia, and also enabled the brands, enterprises, humanities and history of this region to get out of the regional restrictions and develop a broader environment, thus promoting the economic and social prosperity of Inner Mongolia. For example, the culture of Wang 
Zhaojun and the Xanadu culture of the Yuan Dynasty have been accepted by the world through the advertising slogans in different communication media, reflecting the social and economic value of the regional cultures.

Advertising slogans have promoted the cultivation and innovation of the new culture in Inner Mongolia. "Advertising culture is the unity of social culture, regional characteristic culture and popular culture, which conveys a new social and cultural message to people while displaying product information" [12]. As a product of the development of commodity economy, advertising slogans are updated with the times and also make a constant breakthrough in their forms and contents. Moreover, its combination with traditional culture will be inevitably endowed with a new meaning and value, thus capturing the psychological needs of people in the new era and tapping new highlights to produce cultural resonance. As the culture and economy intermingle with each other, the grassland culture of Inner Mongolia also keeps pace with the times and integrates with the industrial development of this region, which adds fresh impetus to the regional development and allows for the innovation of grassland culture through the dissemination of the advertising slogans.

\section{CONCLUSIONS}

It is undeniable that advertising slogans are essentially a means of publicity, and the term derived from Latin originally implies to attract attention, to inform, and to induce. With the continuous development of commercial activities, the purpose of advertising slogans is more clearly to impress people, and it will never change regardless of its purposes for public service, product or tourism. Each language has a national identity, and it will possess a much deeper and valuable meaning to be explored when it is presented as a cultural symbol in the group.

Regional advertising slogans are a special "trademark" of the regional cultures. Although they are not significant in the whole system of written language, they allow people to observe the process of society and civilization from another side, especially based on the universality and popularity of their application. Therefore, this paper also studies the living customs, cultural characteristics and even value inheritance of a certain group of people under different regional and ethnic cultures through advertising slogans, which is of certain reference significance for the study of human culture. Through the study of advertising slogans in Inner Mongolia, this paper can further explore the hidden characteristic cultures, and then make an attempt to research the Mongolian culture and grassland culture, so as to better inherit and carry forward the excellent cultures and enrich the Chinese national cultural treasures.

\section{AUTHORS' CONTRIBUTIONS}

Jian Zhao and Qi Jia contribute equally to this paper.

\section{REFERENCES}

[1] P.A. Chen, An Introduction to Advertising, Higher Education Press, Beijing, 2014.

[2] N. Angelique, A Semantic-Pragmatic Approach to Sentence Structure in Advertising Language. Southern African Linguistics and Applied Language Studies 38(3) (2020) 185-199.

[3] Y.L. Fu, An Empirical Analysis of Copyright, Protection for Advertising Slogans 6 (2016) 62-66.

[4] J. Yang, Cultural and Psychological Functions of Advertising Language. Youth Journalist 17 (2012) 69-70.

[5] W.J. Wu, Application of Rhetorical Usage in Advertising Language, Language Planning, 12 (2012) 71-72.

[6] W.D. Chen, An Introduction to Rhetoric, New Literature and Art Publishing House, Shanghai, 1954.

[7] Y.S. Liu, Remnants of the Book of Songs in the Western Dialect of Inner Mongolia, Journal of Inner Mongolia Normal University (Philosophy and Social Sciences Edition) 3 (1995) 58-63.

[8] Y.F. Gao, Grassland Pastoral: Characteristics and Forms of Grassland Culture, Modern Press, Beijing, 2014.

[9] T. Bhatia, Emotions and Language in Advertising, World Englishes 38(3) (2019) 435-449.

[10] L.M. Guan, Research on the Use of Regional Culture in Tourism Real Estate Advertising: A Case Study of "Kunming Old Street" Project, Yunnan Arts University, Kunming, 2016.

[11] M. Li, Study on the Application and Construction of Advertising Language in the Era of Consumption Culture, Journal of Nantong University (Social Sciences Edition) 36(6) (2020) 129-136.

[12] R.Y. Zhao, Television Advertising from a Cultural Perspective, Contemporary TV (5) (2005) 76. 